\title{
On the parameterization of turbulent fluxes over the tropical Eastern Pacific
}

\author{
G. B. Raga and S. Abarca \\ Centro de Ciencias de la Atmósfera, Universidad Nacional Autónoma de México, 04510 Mexico City, Mexico
}

Received: 24 March 2006 - Published in Atmos. Chem. Phys. Discuss.: 26 June 2006

Revised: 24 October 2006 - Accepted: 1 February 2007 - Published: 9 February 2007

\begin{abstract}
We present estimates of turbulent fluxes of heat and momentum derived from low level $(\sim 30 \mathrm{~m})$ aircraft measurements over the tropical Eastern Pacific and provide empirical relationships that are valid under high wind speed conditions (up to $25 \mathrm{~ms}^{-1}$ ). The estimates of total momentum flux and turbulent kinetic energy can be represented very accurately $\left(r^{2}=0.99\right.$, when data are binned every $\left.1 \mathrm{~ms}^{-1}\right)$ by empirical fits with a linear and a cubic terms of the average horizontal wind speed. The latent heat flux shows a strong quadratic dependence on the horizontal wind speed and a linear relationship with the difference between the air specific humidity and the saturated specific humidity at the sea surface, explaining $96 \%$ of the variance. The estimated values were used to evaluate the performance of three currently used parameterizations of turbulence fluxes, varying in complexity and computational requirements. The comparisons with the two more complex parameterizations show good agreement between the observed and parameterized latent heat fluxes, with less agreement in the sensible heat fluxes, and one of them largely overestimating the momentum fluxes. A third, very simple parameterization shows a surprisingly good agreement of the sensible heat flux, while momentum fluxes are again overestimated and a poor agreement was observed for the latent heat flux $\left(r^{2}=0.62\right)$. The performance of all three parameterizations deteriorates significantly in the high wind speed regime (above $10-15 \mathrm{~ms}^{-1}$ ). The dataset obtained over the tropical Eastern Pacific allows us to derive empirical functions for the turbulent fluxes that are applicable from 1 to $25 \mathrm{~ms}^{-1}$, which can be introduced in meteorological models under high wind conditions.
\end{abstract}

Correspondence to: G. B. Raga

(raga@servidor.unam.mx)

\section{Introduction}

The atmosphere and oceans interact and are coupled through very small-scale processes that are related to the surface turbulent fluxes of momentum and heat (latent and sensible), as well as to trace gas and particle fluxes. Momentum and heat fluxes are important to the atmospheric and oceanic dynamics, while trace gas and particle fluxes constitute sinks and/or sources for their global budgets. Surface entropy fluxes have been found to relate linearly with the intensification of convection in the tropical Eastern Pacific (Raymond et al., 2003). This correlation was more important than that with the local convective available potential energy (CAPE) or with the convective inhibition (CIN). An accurate representation of all these fluxes in large-scale weather and climate models is needed, but the theory is sometimes not adequate and observations are scarce in many regions of the globe.

In this study we utilize high-resolution measurements obtained close to the surface (between 25 and $50 \mathrm{~m}$ a.s.l.) to derive turbulent fluxes of heat and momentum under conditions of high horizontal winds, which are not typically sampled.The measurements are made in the region of the tropical Eastern Pacific where not many studies have been conducted. The tropical Eastern Pacific (Fig. 1a) is a region characterized by well determined rainy and dry seasons. The former is present during the Northern Hemisphere summer, when the Intertropical Convergence Zone (ITCZ) migrates northward. During the dry season, the ITCZ moves South and often there are strong surface winds in the Gulf of Tehuantepec as a result of the interaction of two factors: i) the establishment of a large pressure gradient between the Gulf of Mexico and the Gulf of Tehuantepec due to high pressure systems located in the Gulf of Mexico, and ii) the presence of a gap in the Sierra Madre del Sur, the mountain range that crosses from East to West the Isthmus. While the average height of the mountain range is $2000 \mathrm{~m}$ above sea level, at the central part of the Isthmus it drops to only $\sim 250 \mathrm{~m}$, in a region approximately

Published by Copernicus GmbH on behalf of the European Geosciences Union. 
(b)

(a)
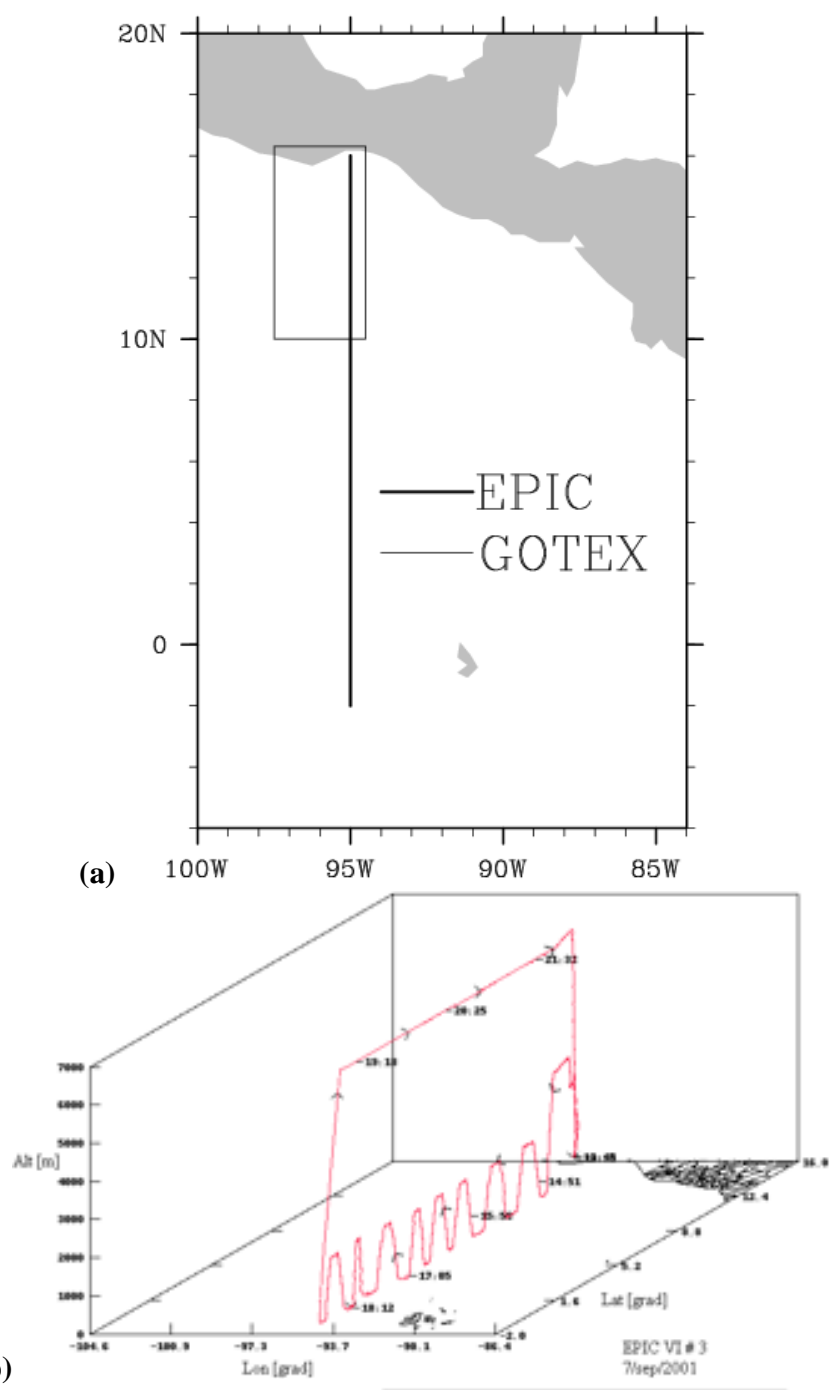

(c)

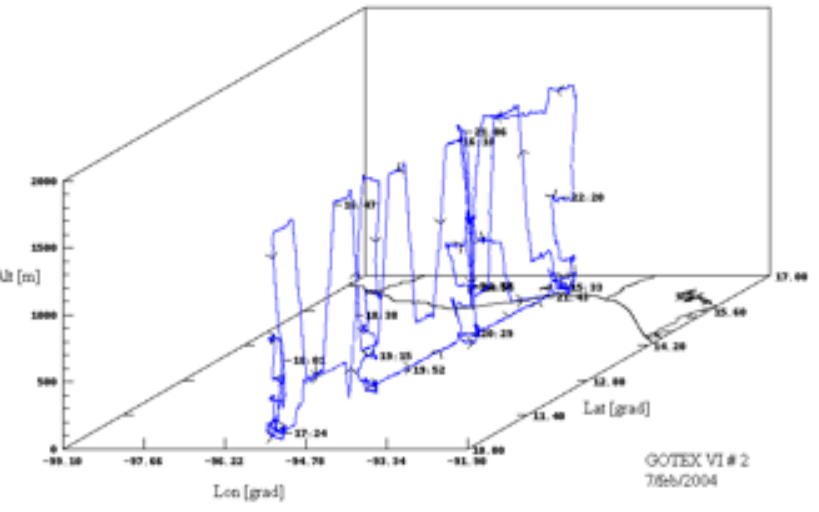

Fig. 1. (a) Geographical location of the region of study. Examples of flight patterns from (b) EPIC and (c) GOTEX.

$40 \mathrm{~km}$ wide (Romero-Centeno et al., 2003). The winds are confined by the topography and accelerate through this gap, resulting in the observations of intense near surface winds over the Gulf of Tehuantepec.
In this study we also examine the dependence of the empirically determined fluxes on the mean variables that are predicted in large scale meteorological models: horizontal wind speed, difference between air and sea surface temperature and difference between air specific humidity and saturated specific humidity at the sea surface. Furthermore, the observations are used to test the validity of three parameterizations currently used in numerical models.

\section{Measurements and methodology}

The data presented in this study were obtained during two field campaigns in which the C-130 instrumented aircraft (operated by the National Center for Atmospheric Research, NCAR) made low-level flights close to the surface of the ocean. Data were obtained from eight flights during the East Pacific Investigation of Climate (EPIC2001), in September and October 2001 (Raymond et al., 2004). The flight patterns alternated between near the surface $(25-50 \mathrm{~m})$ for $10 \mathrm{~min}$ and then at $1600 \mathrm{~m}$ where another level run was made for $\sim 7$ min, heading south along the $95^{\circ} \mathrm{W}$ meridian from $14^{\circ} \mathrm{N}$ to $2^{\circ} \mathrm{S}$ (Fig. 1b). During February 2004, the same aircraft participated in research flights during the Gulf of Tehuantepec Experiment (GOTEX), again making low-level runs, but the patterns were more variable than those during EPIC2001. The low-level segments from eight flights from GOTEX were utilized for this study (Fig. 1c). The height of the mixed layer was $\sim 500 \mathrm{~m}$ and the height of the surface layer was assumed to be around $50-100 \mathrm{~m}$.

The high frequency wind measurements were obtained from the five-hole gust probe system located on the radome of the aircraft. The air temperature was determined from one of the Rosemount thermometers and the specific humidity was derived from one of the Lyman-alpha sensors. A detailed description of the sensors and their performance (resolution, precision and errors) can be found in the web page of the Research Aviation Facility at NCAR (http://www.eol.ucar.edu/ raf/Bulletins/bulletin3.html).

Turbulent fluxes of the different variables were obtained as the covariance of the turbulent fluctuations from the mean values (also called eddy covariances), averaged over time periods of $100 \mathrm{~s}$, which correspond roughly to spatial segments of $10 \mathrm{~km}$ at the typical aricraft speed. The mean values were determined over the same segment. Tests were performed to determine the sensitivity to the averaging period, utilizing averages of $1,5,10,15$ and $20 \mathrm{~km}$. The results indicate that the mean value of the fluxes was independent of the averaging period, but the variance was largest when $1 \mathrm{~km}$ was used. The choice of $10 \mathrm{~km}$ is consistent with other studies (Khelif et al., 2005). This choice of $10 \mathrm{~km}$ averaging period gave a total of 592 segments over which flux estimates were performed. Once the fluxes were estimated, they were plotted against the mean variables and from the visual inspection of those plots, it was possible to identify outliers. These flux 
estimates had values that did not seem to belong to the same statistical population as the rest of the values. The time series of the variables corresponding to the periods when those values were observed, were further explored and some values were defined as outliers. The definition was made subjectively, based on the existence of either a low-frequency change or drift of the variables during the segment and/or the presence of an abrupt change in the magnitude of the variables. In some cases these outliers were linked to large directional shear close to the ocean (perhaps as a result of gust fronts associated with precipitation in the northern regions of the $95^{\circ} \mathrm{W}$ flights during EPIC2001). In other cases, outliers were related to segments that included precipitation (as determined by the presence of water drops in the 2-D-Cloud probe, also part of the $\mathrm{C}-130$ instrumentation). Less than $1 \%$ of the total estimates of fluxes were excluded from the analysis.

\section{Results and discussion}

\subsection{Determination of turbulent fluxes}

The tendency equation for the turbulent kinetic energy (TKE) per unit mass $\left[\bar{e}=0.5 \overline{\left(u_{i}^{\prime 2}\right)}\right]$ can be written as follows (Stull, 1994):

$$
\begin{aligned}
\frac{\partial \bar{e}}{\partial t}+\overline{u_{j}} \frac{\partial \bar{e}}{\partial x_{j}}= & -\overline{\left(u_{i}^{\prime} u_{j}^{\prime}\right)} \frac{\partial \overline{u_{i}}}{\partial x_{j}}+\delta_{i 3} \frac{\overline{\left(u_{i}^{\prime} \theta_{v}^{\prime}\right)}}{\bar{\theta}_{v}} g-\frac{\partial \overline{\left(u_{j}^{\prime} e^{\prime}\right)}}{\partial x_{j}} \\
& -\frac{1}{\bar{\rho}_{\text {air }}} \frac{\partial\left(p^{\prime} u_{i}^{\prime}\right)}{\partial x_{i}}-\varepsilon
\end{aligned}
$$

where, $\overline{u_{j}}$ correspond to the mean wind velocities in the 3 dimensions $(j=1,3) ; u_{j}^{\prime}$, to the turbulent fluctuations of the wind; $\theta^{\prime} v$, to the turbulent fluctuation of the virtual potential temperature; $p^{\prime}$, to the turbulent fluctuation of the pressure; $\bar{\rho}_{\text {air }}$ and $\bar{\theta}_{v}$, to the mean air density and mean virtual potential temperature, respectively; and $\varepsilon$, to the turbulent dissipation rate. The terms on the left-hand side of this equation correspond to the local tendency and the advection by the mean wind. The terms on the right-hand side of the equation correspond to the production/destruction of turbulent kinetic energy by shear of the mean wind, the production/destruction by buoyancy, the transport term due to turbulent eddies, the redistribution of turbulent kinetic energy by pressure perturbations and the viscous dissipation.

An equivalent expression can be written for the horizontal momentum flux (TMF):

$$
\begin{aligned}
\frac{\partial\left(\overline{u_{i}^{\prime} w^{\prime}}\right)}{\partial t}+\overline{u_{j}} \frac{\partial\left(\overline{u_{i}^{\prime} w^{\prime}}\right)}{\partial x_{j}} & =-\left(\overline{u_{i}^{\prime} u_{j}^{\prime}}\right) \frac{\partial \bar{w}}{\partial x_{j}}-\left(\overline{w^{\prime} u_{j}^{\prime}}\right) \frac{\partial \overline{u_{i}}}{\partial x_{j}} \\
& +\frac{g}{\overline{\theta_{v}}}\left(\overline{u_{i}^{\prime} \theta_{v}^{\prime}}+\delta_{i 3} \overline{w^{\prime} \theta_{v}^{\prime}}\right) \\
& -\frac{\partial\left(\overline{u_{i}^{\prime} u_{j}^{\prime} w^{\prime}}\right)}{\partial x_{j}}-\frac{1}{\bar{\rho}_{\text {air }}}\left(\frac{\partial \overline{p^{\prime} w^{\prime}}}{\partial x_{i}}\right. \\
& \left.+\frac{\partial \overline{p^{\prime} u_{i}^{\prime}}}{\partial z}\right)+\frac{p^{\prime}}{\bar{\rho}_{\text {air }}}\left(\frac{\partial \overline{u_{i}^{\prime}}}{\partial z}+\frac{\overline{\partial w^{\prime}}}{\partial x_{i}}\right)-2 \varepsilon_{w u_{i}}
\end{aligned}
$$

where $i$ and $j=1,2$. The terms in this equation (from left to right) correspond to the local tendency of the TMF, the advection by the mean wind, the production/destruction by shear of the mean wind, the production/destruction by buoyancy, the transport term due to turbulent eddies and the redistribution of TMF due to pressure correlations (which are small and usually neglected) and due to the return-to-isotropy term and finally, the viscous dissipation term. The Coriolis and molecular diffusion terms have been neglected.

Inspection and scale analysis of Eqs. (1) and (2) indicate that the dominant terms are: the advection and production by shear terms, which are proportional to the cubic power of the velocity scale, and the buoyancy and transport by pressure perturbations terms, which are a linear function of the velocity scale. This scale analysis suggests that the TKE and the TMF derived from the observations would likely have a dependence on the horizontal wind speed involving a linear and a cubic terms.

The derived total horizontal momentum flux and the turbulent kinetic energy indeed present a strong non-linear relationship with the mean horizontal wind, as shown in Figs. 2a and $b$. Note that the observations presented in these figures are derived from two different field programs and it appears that the same functional form is applicable in both cases, since the observations do not cluster into two separate populations. These figures also highlight the range of horizontal wind speeds over which the observations were made, from only a couple up to $25 \mathrm{~ms}^{-1}$. Note that there are many observations with wind speeds above $15 \mathrm{~ms}^{-1}$, which is not frequently found.

The individual data points were binned in intervals of horizontal wind speeds of $1 \mathrm{~ms}^{-1}$ and the best-fit curves were determined for these binned data. In agreement with the scale analysis of Eqs. (1) and (2), a cubic polynomial was fit to the data. The non-linear regression yields a cubic and a linear term in each case, of the following form:

$\mathrm{TMF}=\mathrm{aV}+\mathrm{bV}^{3}$
$\mathrm{TKE}=\mathrm{cV}+\mathrm{dV}^{3}$

where $\mathrm{V}$ corresponds to the magnitude of the horizontal wind (in $\mathrm{ms}^{-1}$ ) and $\mathrm{a}=3.39 \mathrm{E}-03 \mathrm{~N} \mathrm{~s} \mathrm{~m}^{-3}$, $\mathrm{b}=7.72 \mathrm{E}-05 \mathrm{~N} \mathrm{~s}^{3} \mathrm{~m}^{-5}, \quad \mathrm{c}=3.01 \mathrm{E}-02 \mathrm{~ms}^{-1} \quad$ and $\mathrm{d}=2.66 \mathrm{E}-04 \mathrm{~s} \mathrm{~m}^{-1}$. Note that the estimates of TMF 
a)

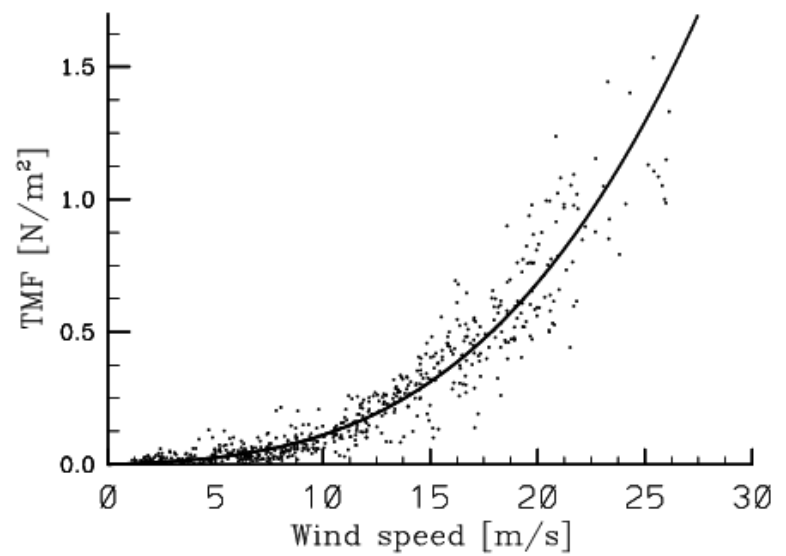

b)

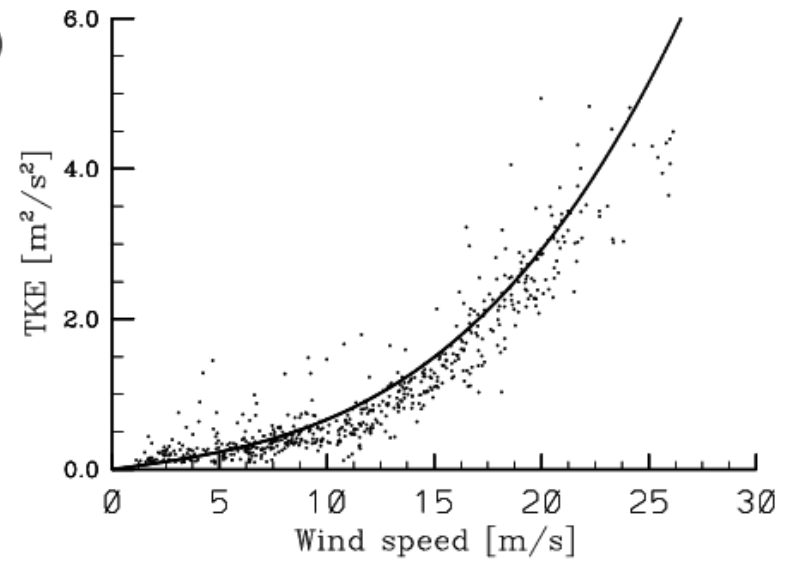

Fig. 2. (a) Turbulent horizontal momentum flux (TMF) and (b) Turbulent kinetic energy (TKE), as a function of the horizontal wind speed. The datapoints $(\sim 600)$ correspond to eddy covariances averaged over $100 \mathrm{~s}$. The solid lines correspond to best fits determined when the data were binned in intervals of $1 \mathrm{~ms}^{-1}$ (see text and Eqs. 3 and 4).

and TKE in Figs. 2a and $\mathrm{b}$ show only moderate dispersion from the respective best fit curves. Thus, the correlation coefficients are 0.99 for both the TMF and the TKE.

The relevant budget equation for the turbulent specific humidity flux is given by:

$$
\begin{aligned}
\frac{\partial \overline{\left(q^{\prime} u_{i}^{\prime}\right)}}{\partial t}+\overline{u_{j}} \frac{\partial \overline{\left(q^{\prime} u_{i}^{\prime}\right)}}{\partial x_{j}}= & -\overline{\left(q^{\prime} u_{j}^{\prime}\right)} \frac{\partial \overline{u_{i}}}{\partial x_{j}}-\overline{\left(u_{i}^{\prime} u_{j}^{\prime}\right)} \frac{\partial \bar{q}}{\partial x_{j}} \\
& -\frac{\partial \overline{\left(q^{\prime} u_{i}^{\prime} u_{j}^{\prime}\right)}}{\partial x_{j}}+\delta_{i 3} \overline{\frac{\left.q^{\prime} \theta_{v}^{\prime}\right)}{\bar{\theta}_{v}}} g \\
& +\frac{1}{\overline{\bar{\rho}_{\text {air }}}} \frac{\overline{\left(p^{\prime} \partial q^{\prime}\right)}}{\partial x_{j}}-2 \varepsilon_{q}
\end{aligned}
$$

where $\bar{q}$ and $q^{\prime}$ correspond to the mean and the turbulent perturbation of the specific humidity, respectively, and the other variables were introduced when discussing Eqs. (1) and (2). Scale analysis of Eq. (5) indicates that the terms range in
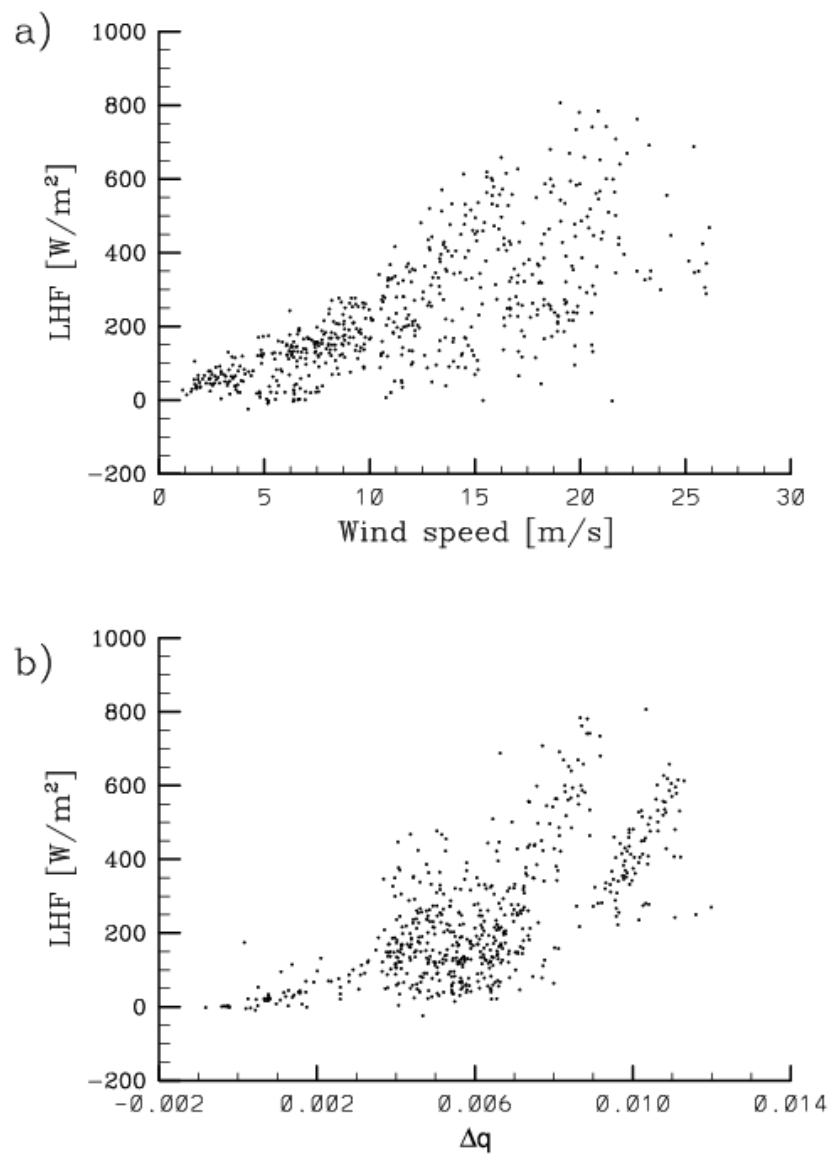

Fig. 3. Latent heat flux as a function of (a) horizontal wind speed and (b) difference of saturation specific humidities at the sea surface and at the height of the measurements.

magnitude from $10^{-4}$ and $10^{-11}$, with the production term due to the gradient of the mean specific humidity being the dominant one and proportional to $V^{2}$ and $\Delta q$. As shown in Fig. 3, the vertical latent heat flux $\left(\mathrm{LHF}=\rho_{\mathrm{air}} \mathrm{L}_{\mathrm{v}} \overline{\mathrm{w}^{\prime} \mathrm{q}^{\prime}}\right)$ has a strong (quadratic) dependence on the horizontal wind speed (Fig. 3a), while only a linear relationship with the difference of air specific humidity and saturated specific humidity at the sea surface (Fig. 3b). These dependences are consistent with the scale analysis of the corresponding vertical component of Eq. 5. The observed LHF cover a range from close to 0 up to $500 \mathrm{Wm}^{-2}$, increasing with the horizontal wind speed. The LHF estimated as the eddy covariance was stratified only in terms of the horizontal wind speed in bins of $1 \mathrm{~ms}^{-1}$, and the following empirical relationship was derived:

$\mathrm{LHF}=\mathrm{a}+\mathrm{bV}^{2}+\mathrm{c} \Delta \mathrm{q}$

where $\Delta \mathrm{q}=\left[\mathrm{q}_{\text {air }}-\mathrm{qs}_{s s}\right]$ and $\mathrm{a}=-100 \mathrm{~W} \mathrm{~m}^{-2}, \mathrm{~b}=0.772 \mathrm{Ws}^{2}$ $\mathrm{m}^{-4}$ and $\mathrm{c}=34216 \mathrm{~W} \mathrm{~m}^{-2}$. Note that for the LHF (Fig. 3), the observations present more scatter than for the TMF and the TKE (Fig. 2). Nevertheless, the relationship given by Eq. (6) explains $96 \%$ of the variance for a horizontal wind range 


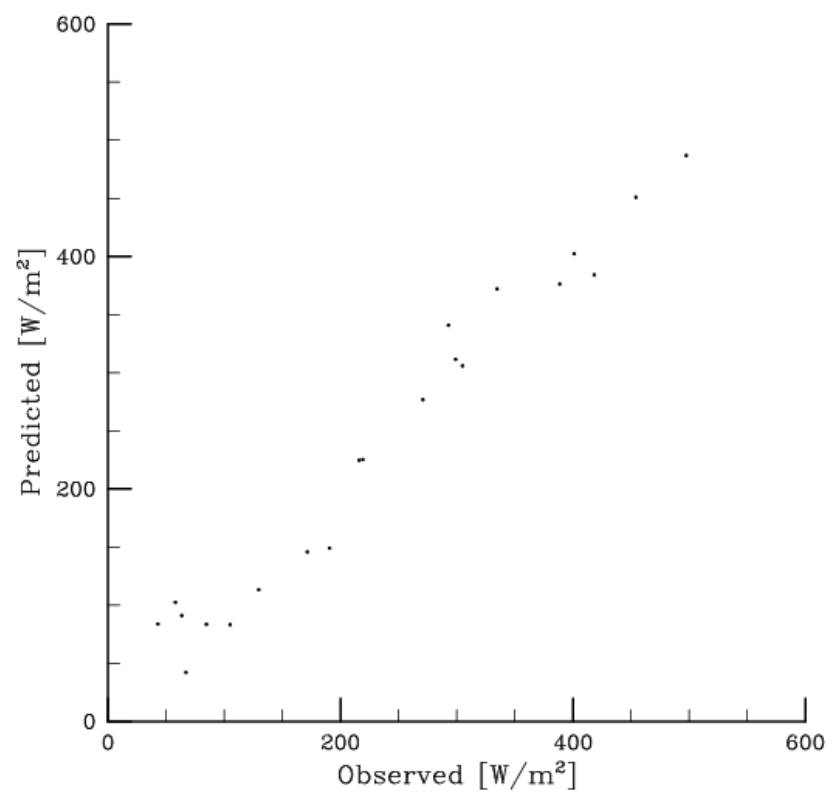

Fig. 4. Dispersion diagram of predicted (y-axis) versus observed values of the latent heat fluxes, utilizing the empirical fit: $L H F=a+b$ $\mathrm{V}^{2}+\mathrm{c} \Delta \mathrm{q}$ (see text).

between 1 and $20 \mathrm{~m} \mathrm{~s}^{-1}$. It is possible that the larger scatter in the LHF is related to the large range in ambient conditions between summer and winter, with sea surface temperature (SST) varying in the region of the tropical Eastern Pacific. During the EPIC project (September and October 2001) both air and SSTs are warmer and the specific humidity is higher than during GOTEX (February 2004). Figure 4 shows the dispersion diagram between observed and predicted latent heat fluxes. The observed fluxes are calculated from the eddy covariance and then binned every $\mathrm{ms}^{-1}$, while the predicted values are derived using Eq. (6). It is rather remarkable that such a simple function can reproduce quite accurately the latent heat fluxes covering a wide range of wind speeds, given that the magnitude of the flux also varies over a large range.

The observations were also used to estimate the vertical sensible heat flux $\left(\mathrm{SHF}=\rho_{\text {air }} \mathrm{c}_{\mathrm{p}} \overline{\mathrm{W}^{\prime} \theta^{\prime}}\right)$. Figures $5 \mathrm{a}$ and $\mathrm{b}$ present the estimates as functions of the horizontal wind speed and of the difference between the sea surface and the air temperature at the height of the observations, respectively. It can been seen in Fig. 5a, that the SHF exhibited very little dependence on the horizontal wind speed. This figure shows a very large scatter in the magnitude of the SHF, with both positive and negative values present. This range in SHF estimates is related to the large range on ambient conditions (summer vs. winter) over which the measurements were taken. Note that in some cases of high wind speed (e.g. $15 \mathrm{~ms}^{-1}$ ), observations show a range of values from -50 to $+50 \mathrm{Wm}^{-2}$, indicating no clear relationship between the SHF and the wind speed. In contrast to this lack of relationship, a clear linear relationship with the air-sea surface temperature
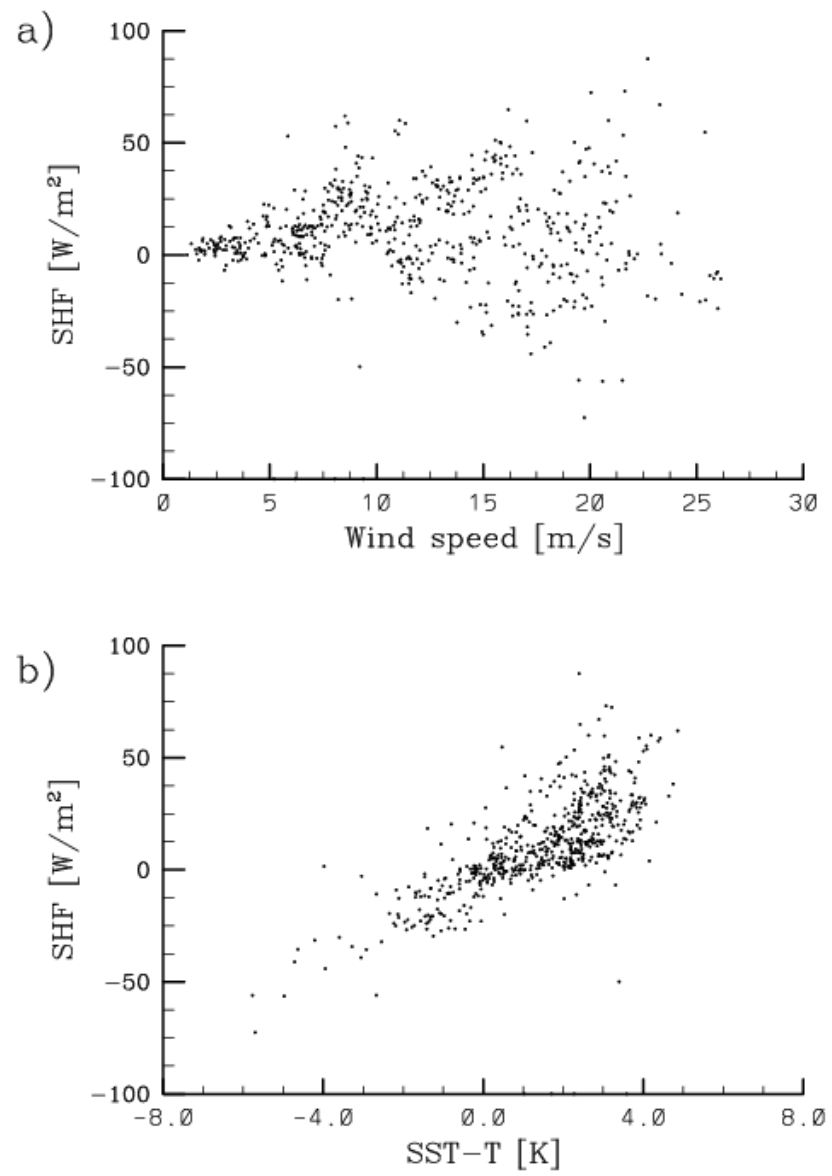

Fig. 5. Sensible heat flux as a function of (a) horizontal wind speed and (b) temperature difference at the sea surface and at the height of the measurements.

difference was observed (Fig. 5b), as expected from the scale analysis. This dependence shows less scatter than in Fig. 5a, but again larger scatter than estimates of the TMF and the TKE.

The SHF estimated as the eddy covariance was stratified only in terms of the horizontal wind speed in bins of $1 \mathrm{~ms}^{-1}$, and the following empirical relationship was derived:

$\mathrm{SHF}=\mathrm{a}+\mathrm{b} \Delta \mathrm{T}$

where $\Delta \mathrm{T}=\left[\mathrm{T}_{s s}-\mathrm{T}_{\text {air }}\right]$ in Kelvin and $\mathrm{a}=1.4 \mathrm{~W} \mathrm{~m}^{-2}$ and $\mathrm{b}=9.1 \mathrm{~W} \mathrm{~m}^{-2} \mathrm{~K}^{-1}$. A correlation coefficient of 0.99 is obtained, based on the binned data.

These results presented here provide simple and accurate formulae for the turbulent fluxes of latent and sensible heat, momentum and TKE over the ocean that can be introduced in mesoscale and large scale weather and climate models, to test their sensitivity over a wide range of observed horizontal wind speeds. 


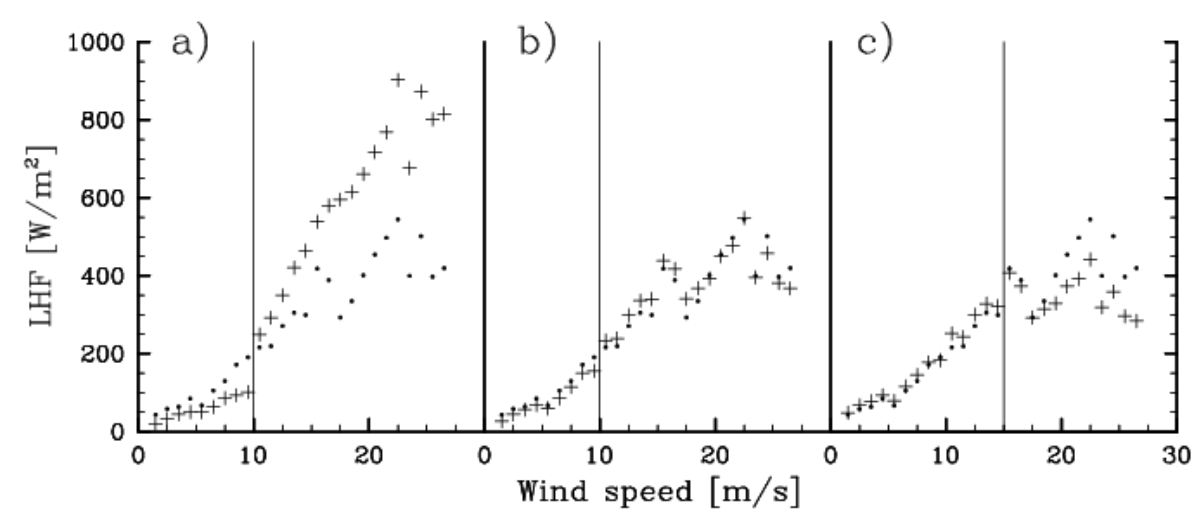

Fig. 6. Turbulent latent heat fluxes from observations (dots) and derived from the three parameterizations (crosses) as a function of horizontal wind speed (binned in $1 \mathrm{~ms}^{-1}$ intervals), for (a) K02, (b) M97 and (c) F96. Note that there is a change in performance of the parameterizations at $10 \mathrm{~ms}^{-1}$ (K02 and M97) and at $15 \mathrm{~ms}^{-1}$ (F96), indicated by the vertical lines.

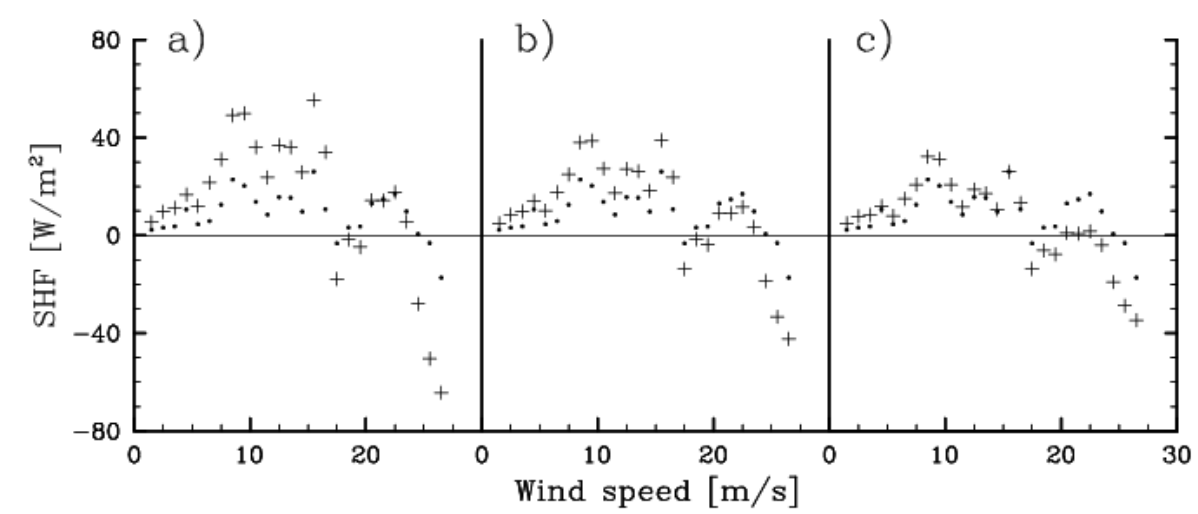

Fig. 7. Turbulent sensible heat fluxes from observations (dots) and derived from the three parameterizations (crosses) as a function of horizontal wind speed (binned in $1 \mathrm{~ms}^{-1}$ intervals), for (a) K02, (b) M97 and (c) F96.

\subsection{Comparison with parameterizations}

The turbulent fluxes derived from the observations (using the eddy covariance method) were compared against the resulting fluxes from three different parameterizations currently utilized, which vary widely in level of complexity and computational requirements. The comparison is presented for latent heat fluxes (Fig. 6), sensible heat fluxes (Fig. 7) and horizontal momentum fluxes (Fig. 8), shown in these figures as a function of the horizontal wind speed. Tables 1,2 and 3 present a quantification of the performace of each parameterization, compared against the results from the covariance method, for the three turbulent fluxes mentioned.

The parameterization presented by Kara et al. (2000), including the corrections introduced by Kara et al. (2002, herein denoted as K02), are in moderate agreement with the observations, as can be seen in Figs. 6a, 7a and 8a. In particular, the latent heat fluxes (Fig. 6a) derived using the parameterization $\mathrm{K} 02$ are more variable than the observations derived by eddy covariance method (which are here considered to be the "reference values" for the fluxes). The correla- tion coefficient is only 0.62 (see Table 1 ), with a difference in the mean of the population about $34 \%$ from the observations. Note the different behaviour of the latent heat flux calculated using the K02 parameterization for low vs. high wind speeds, indicated by the vertical line in Fig. 6a. The parameterized values underestimate the "reference values" for wind speeds lower than $10 \mathrm{~m} \mathrm{~s}^{-1}$ and largely overestimate the "reference values" for higher wind speeds. The sensible heat fluxes using K02 (Fig. 7a) are systematically over-estimated for wind speeds lower than about $15 \mathrm{~m} \mathrm{~s}^{-1}$ and exhibit the largest variability of the three parameterizations evaluated, as can be seen comparing the three panels in Fig. 7. The correlation coefficient is 0.79 (Table 2). The inclusion of the corrections presented by Kara et al. (2002) led to a slight improvement in the representation of all fluxes, particularly of the momentum flux. Nevertheless, this improvement is not enough to get a closer agreement with the "reference values" obtained by the covariance method, leading to an overestimate in $93 \%$ of the cases (see Table 3). In summary, the K02 parameterization performs only moderately well for sensible heat fluxes 


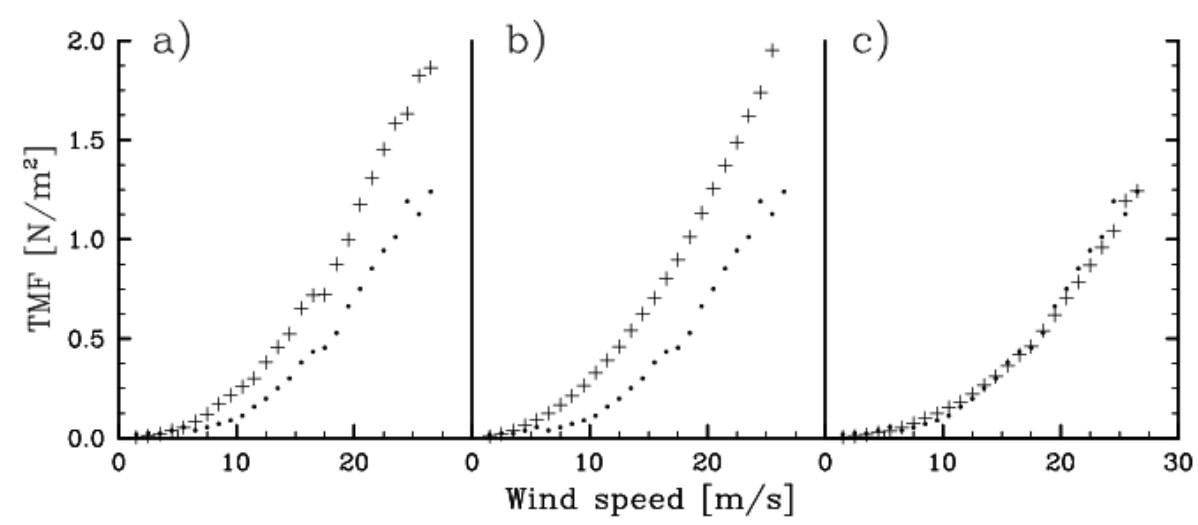

Fig. 8. Turbulent horizontal momentum fluxes from observations (dots) and derived from the three parameterizations (crosses) as a function of horizontal wind speed (binned in $1 \mathrm{~ms}^{-1}$ intervals), for (a) K02, (b) M97 and (c) F96.

Table 1. Statistical parameters for the different methods of estimating the turbulent latent heat flux (COV: covariance method, K02: Kara et al., 2002; M97: Mendoza et al., 1997; F96: Fairall et al., 1996).

\begin{tabular}{lcccc}
\hline LHF & COV & K02 & M97 & F96 \\
\hline Average $\left[\mathrm{W} / \mathrm{m}^{2}\right]$ & 238.9 & 321.0 & 241.5 & 234.2 \\
RMSE $\left[\mathrm{W} / \mathrm{m}^{2}\right]$ & & 194.4 & 60.2 & 65.8 \\
Correlation coefficient & & 0.62 & 0.88 & 0.87 \\
\hline
\end{tabular}

(Fig. 7a) and over-estimates the horizontal momentum fluxes (Fig. 8a) at almost all wind speeds. It constitutes the poorest comparison of the three parameterizations evaluated with the observed latent heat fluxes (Fig. 6).

Mendoza et al. (1997, herein denoted M97) includes a simple parameterization of the air-sea turbulent fluxes to predict sea surface temperature anomalies in the Gulf of Mexico, based on parameterizations from the literature (Isemer and Hasse, 1987, for the wind stress and Adem et al., 1994, for the sensible and latent heat fluxes). The parameterization does not require iterative calculations and the drag coefficients are described in terms of the Richardson number. The evaluation of the performance of this parameterization against the fluxes derived by eddy covariance in the tropical Eastern Pacific suggests that the parameterization is fairly good given its simplicity. It performs moderately well for latent (Fig. 6b) and sensible heat fluxes (Fig. 7b), particularly at low wind speeds, but over-estimates the horizontal momentum fluxes (Fig. 8b) at almost all wind speeds. Tables 1 and 2 show that the correlation coefficients are 0.88 and 0.78 for the latent and sensible heat fluxes, respectively. The horizontal momentun flux is overestimated $87 \%$ of the cases (see Table 3 ). Note that the performance of the latent heat flux as a function of horizontal wind speed is different for values lower and than $10 \mathrm{~m} \mathrm{~s}^{-1}$. As can be seen in Fig. 6b, the fluxes calculated using the M97 parameterization consti-
Table 2. Statistical parameters for the different methods of estimating the turbulent sensible heat flux (COV: covariance method, K02: Kara et al., 2002; M97: Mendoza et al., 1997; F96: Fairall et al., 1996).

\begin{tabular}{lcccc}
\hline SHF & COV & K02 & M97 & F96 \\
\hline Average $\left[\mathrm{W} / \mathrm{m}^{2}\right]$ & 10.93 & 22.11 & 16.77 & 11.48 \\
RMSE $\left[\mathrm{W} / \mathrm{m}^{2}\right]$ & & 32.18 & 19.45 & 12.65 \\
Correlation coefficient & & 0.79 & 0.78 & 0.76 \\
\hline
\end{tabular}

Table 3. Statistical parameters for the different methods of estimating the turbulent horizontal momentum flux (COV: covariance method, K02: Kara et al., 2002; M97: Mendoza et al., 1997; F96: Fairall et al., 1996).

\begin{tabular}{lcccc}
\hline TMF & COV & K02 & M97 & F96 \\
\hline Average $\left[\mathrm{W} / \mathrm{m}^{2}\right]$ & 0.27 & 0.44 & 0.51 & 0.27 \\
RMSE $\left[\mathrm{W} / \mathrm{m}^{2}\right]$ & & 0.25 & 0.32 & 0.09 \\
Overestimation $(\%)$ & & 93 & 87 & 57 \\
\hline
\end{tabular}

tute an under-estimate of the "reference values" (those determined by the covariance method) for wind speed less than $10 \mathrm{~m} \mathrm{~s}^{-1}$ and represent an over-estimate for higher winds.

The parameterization presented in Fairall et al. (1996) was derived from the TOGA-COARE field project (herein denoted as F96). The calculation of the turbulent fluxes is based on concepts of Monin-Obhukov similarity, involves an iterative method and is the most computationally expensive of the three parameterizations evaluated. The latent heat fluxes compared favorably with the "reference values" estimated by the covariance method (Fig. 6c), but note that there is a slight over-estimate for low wind speeds and a systematic under-estimate for wind speeds above $15 \mathrm{~m} \mathrm{~s}^{-1}$, with also much larger variability. The comparison of the 
sensible heat fluxes against the "reference values" is the poorest of the three parameterizations evaluated (with a correlation coefficient of 0.76 , Table 1 ), as the parameterization is clearly under-estimating the observations for wind speeds above $15 \mathrm{~m} \mathrm{~s}^{-1}$. This bias may be due to the fact that the fluxes depend strongly on the temperature difference rather than on the horizontal wind speed. There is no clear explanation for this transition in the behavior of the parameterized values at a particular horizontal wind speed, but it may be because the parameterization may have been derived from observations at lower wind speeds than those sampled in this study. In summary, the performance of the F96 parameterization is fairly good for all fluxes for wind speeds lower than $15 \mathrm{~m} \mathrm{~s}^{-1}$, and it particularly performs well for momentum fluxes at even very high horizontal wind speeds, as can be seen in Fig. 8c. and from the statistics in Table 3.

There are some interesting features present in Figs. 6, 7 and 8 that are worth noting at this point. Both the latent heat and horizontal momentum fluxes show a clear dependence with the wind speed, indicating an increase in those fluxes with the horizontal wind speed. This is obvious both for the "reference values" determined by the covariance method and for all three parameterizations evaluated. In contrast, the sensible heat fluxes (Fig. 7) show no monotonic response as a function of wind speed. This behaviour is observed in all estimates, the covariance method and the three parameterizations. In all cases, there is an increase in the SHF with horizontal wind speeds for values lower than $10 \mathrm{~ms}^{-1}$ and no distinguishable trend for higher wind values. For the strongest wind observed (close to $25 \mathrm{~ms}^{-1}$ ), the estimates from the covariance method show negative $\mathrm{SFH}$ at $30 \mathrm{~m}$. The reason for this is possibly that these stronger winds were associated with some upwelling of colder seawater, so that the sensible heat was transferred from the atmosphere to the ocean. The three parameterizations perform moderately well for low wind speeds (below $10 \mathrm{~ms}^{-1}$ ), with performance becoming increasingly worse as wind speed increases. The correlation coefficients are shown in Table 2, between 0.76 and 0.79 for each parameterization, with significant mean root square errors.

The turbulent horizontal momentum fluxes calculated by the covariance method present a monotonic increase with increasing wind speed (Fig. 8), behavior that is reproduced by all three parameterizations. Nevertheless, only F96 is able to reproduce the magnitude of the fluxes, slightly overestimating the observations for winds speeds below $10 \mathrm{~ms}^{-1}$ and underestimating them for higher winds speeds. The parameterizations of K02 and M97 systematically overestimate the magnitude of the fluxes, by up to $90 \%$. Such large overestimates would lead to an erroneous momentum transfer in numerical models where these parameterizations were included.

\section{Final remarks}

Empirical relationships have been determined for the latent and sensible heat fluxes as well as the total horizontal momentum flux and turbulent kinetic energy in a wind speed range from 1 to $25 \mathrm{~m} \mathrm{~s}^{-1}$ (for $10 \mathrm{~km}$ averages), applicable over the tropical Eastern Pacific. This range in velocity is larger than previous studies have explored, and, in addition, the Eastern Pacific is a region that has been largely neglected in observational studies. Moreover, because the sea surface temperature in the Eastern Pacific rapidly changes through the sea surface temperature front (observed between $1-2^{\circ} \mathrm{N}$ ), the range of sensible heat fluxes sampled was also large.

The comparison with three currently used parameterizations has shown that the performance of each parameterization as a function of horizontal wind speed is different. F96, derived for TOGA-COARE provides the best results, when applied to the tropical Eastern Pacific. The parameterization presented by M97 and currently used at our research center in Mexico gives a surprisingly good agreement given its simplicity. In fact it performs better than K02 for latent and sensible heat fluxes.

The Working Group on Ocean Model Development of the Climate Variability and Predictability Program (http://www. eprints.soton.ac.uk/91979; WCRP Informal Report 14/2002) is recommending the use of $\mathrm{K} 02$ in coupled climate models. Our results indicate that the latent and sensible heat fluxes derived from the K02 parameterization have a different behavior under low and high wind conditions and may not adequately represent those fluxes in our region of study. Moreover, the momentum fluxes may also be mis-represented, potentially leading to erroneous predictions. We recommend that further testing of the parameterization similar to the one presented in this study, be carried out before it is implemented in more climate models.

Acknowledgements. The authors are grateful to D. Raymond (Lead PI for EPIC) and K. Melville and C. Friehe (Co-PI for GOTEX) for allowing our participation in those projects. We are indebted to the crews and ground staff of the C-130 who generously supported our involvement during the installation of equipment on the aircraft and throughout the field campaigns. This study was partially funded by a grant from the Mexican Council for Science and Technology (Conacyt-33319).

Edited by: W. E. Asher

\section{References}

Adem, J., Villanueva, E. E., and Mendoza, V. M.: Preliminary experiments in the prediction of sea surface temperature anomalies in the Gulf of Mexico, Geofis. Int., 31(1), 21-34, 1994.

Fairall, C., Bradley, E., Rogers, D., Edson, J., and Young, G.: Bulk parameterization of air-sea fluxes for Tropical Ocean-Global Atmosphere Coupled-Ocean Atmosphere Response Experiment, J. Geophys. Res., 101, 3747-3764, 1996. 
Isemer, H. J. and Hasse, L.: The Bunker Climate Atlas of the North Atlantic Ocean, Vol. 2. Air-Sea Interactions, Springer-Verlag, Berlin, 252 pp., 1987.

Kara, A. B., Rochford, P., and Hurlburt, H.: Efficient and accurate bulk parameterizations of air-sea fluxes for use in general circulation models, J. Atmos. Oceanic. Technol., 17, 1421-1438, 2000 .

Kara, A. B., Rochford, P., and Hurlburt, H.: Air-sea flux estimates and the 1997-1998 ENSO event, Bound. Layer. Meteorol., 103, 439-458, 2002.

Khelif, D., Friehe, C. A., Jonsson, H., Wang, Q., and Kalogiros, J.: Wintertime Boundary-Layer Structure and Air-Sea Interaction over the Japan/East Sea, Deep Sea Res. Part II, 52, 15251546, 2005.

Mendoza, V., Villanueva, E., and Adem, J.: Numerical experiments on the prediction of sea surface temperature anomalies in the Gulf of Mexico, J. Mar. Syst., 13, 83-99, 1997.
Raymond, D., Esbensen, S., Paulson, C., Gregg, M., Bretherton, C., Petersen, W., Cifelli, R., Shay, N., Ohlmann, C., and Zuidema, P.: EPIC2001 and the coupled ocean-atmosphere system of the tropical East Pacific, Bull. Amer. Meteorol. Soc., 85, 1341-1354, 2004.

Raymond, D., Raga, G. B., Bretherton, C., Molinari, J., LopezCarrillo, C., and Fuchs, Z.: Convective forcing in the Intertropical convergence zone of the Eastern Pacific, J. Atmos Sci., 60, 2064-2082, 2003.

Romero-Centeno, R., Zavala-Hidalgo, J., Gallegos, A., O’Brien, J. J.: Isthmus of Tehuantepec wind climatology and ENSO signal, J. Climate, 16, 2628-2639, 2003.

Stull, R.: Boundary Layer Meteorol., Reidel Eds., 666 pp., 1994. 